\title{
Modeling of Surface Roughness Effects on Glaze Ice Accretion*A
}

\author{
R. John Hansman, Jr.* and Keiko Yamaguchi† \\ Department of Aeronautics and Astronautics \\ Massachusetts Institute of Technology \\ Cambridge, Massachusetts \\ Brian Berkowitz\# \\ Sverdrup Technology, Inc. \\ Middleburg Heights, Ohio \\ and \\ Mark Potapczuk** \\ NASA Lewis Research Center \\ Clevland, Ohio
}

\begin{abstract}
A series of experimental investigations focused on studying the cause and effect of roughness on accreting glaze ice surfaces were conducted. Detailed microvideo observations were made of glaze ice accretions on 1" to 4" diameter cylinders in three icing wind tunnels ( the Data Products of New England six inch test facility, the NASA Lewis Icing Research Tunnel, and the B.F. Goodrich Ice Protection Research Facility). Infrared thermal video recordings were made of accreting ice surfaces in the Goodrich facility. Distinct zones of surface water behavior were observed; a smooth wet zone in the stagnation region with a uniform water film; a rough zone where surface tension effects caused coalescence of surface water into stationary beads; a horn zone where roughness elements grow into horn shapes; a runback zone where surface water ran back as rivulets; and a dry zone where rime feathers formed. The location of the transition from the smooth to the rough zone was found to migrate with time towards the stagnation point. The behavior of the transition appeared to be controlled by boundary layer transition and bead formation mechanisms at the interface berween the smooth and rough zones. Regions of wet ice growth and enhanced heat transfer were clearly visible in the infrared video recordings of glaze ice surfaces. A simple multi-zone modification to the current glaze ice accretion model was proposed to include spatial variability in surface roughness. A preliminary version of this model was implemented on the LEWICE ice accretion code and compared with experimental ice shapes. For the two cases run the multi-zone model significantly improved the prediction of the glaze ice shapes.
\end{abstract}

\subsection{Introduction}

Current efforts to analyticaily model glaze ice accretion are hampered by insufficient knowledge of the accreting ice surface roughness. In glaze icing, which normally occurs at temperatures near freezing or high liquid water contents, there is insufficient convective heat transfer to remove all of the latent heat of freezing of the impinging supercooled water droplets. The local ice accretion rate is, therefore, controlled by the local convective heat transfer. The droplet impingement behavior also

\footnotetext{
* Associate Professor, Associate Fellow AIAA.

$\dagger$ Research Assistant, Student Member AIAA.

\# Engineering Associate.

** Aerospace Engineer, Member ALAA.

Copyright $\odot 1988$ by M.I.T. Published by the American Instinte of Aeronautics and Astronautics, Inc. with permission.

*AIAA-89-0734, 27th Aerospace Sciences Meeting, 1989.

ASome original figures were not available at time of publication.
}

plays an important role in determining where on the surface this wet growth occurs and is the controlling factor in dry or rime ice growth where there is sufficient cooling to freeze the droplets on impact.

The local convective heat transfer from a surface is known to be strongly dependent on the ice surface roughness. ${ }^{1}$ Because of the importance of the heat transfer behavior on the ice accretion rate, the surface roughness becomes an important factor modeling glaze ice accretion. Current analytical models such as LEWICE ${ }^{2}$ generally assume that the surface roughness is uniform and the effective sand grain roughness $k$ is used as an input parameter in the code. In some cases ad hoc spatial heat transfer distributions have been used. ${ }^{3}$ The magnitude of the roughness parameter $k$ is normally determined empirically by comparison of predicted and experimental ice accretion.

The erratic performance of glaze ice accretion models and the empirical manner in which the surface roughness is treated indicates the need for a more deterministic treatment of the surface roughness. In the following, experimental investigations focused on the roughness of accreting glaze ice surfaces will be presented as well as preliminary results of a simple modification to the LEWICE code which attempts to treat the ice surface roughness in a more physical manner.

\subsection{Experimental Setup For Ice Surface Observations}

\subsection{Experimental Facilities}

Detailed observations of accreting ice surface roughness were made at several experimental icing facilities. These included the Data Products of New England small icing wind tunnel ( $\left.6^{\prime \prime} X 6^{\prime \prime}\right)$, the NASA Icing Research Tunnel ( 9 X $\left.7^{\prime}\right)$ and the B.F. Goodrich Icing Wind Tunnel ( $\left.2^{\prime} X 4^{\prime}\right)$. In the following these facilities will be designated as DP, IRT, and BFG respectively

\subsection{Photographic Setup}

Detailed photographic observations of the behavior of surface water and formation of ice roughness on cylinders during glaze ice accretion were made in the three facilities described above. Cylinder diameters from 1 " to 4 " were 
observed. Free stream velocities of 100 and $150 \mathrm{kts}$ were run at liquid water contents up to $1.5 \mathrm{~g} / \mathrm{m}^{3}$. Tunnel total air temperatures varied from $0^{\circ} \mathrm{C}$ to $-10^{\circ} \mathrm{C}$ with some colder runs made for calibration purposes. In addition, a thermal infrared (IR) video system was used during the BFG tests to observe the relationship between surface temperature and surface roughness in glaze icing conditions.

The photographic setup used in the DP and BFG tests is shown in Fig. 1. The test articles were cylinders which horizontally spanned the test section. The test section walls were either plexiglass (DP) or heated glass (BFG) to provide photographic access. Scale reference was provided by a grid mounted on a thin splitter plate at the midplane of the test section. A CCD microvideo (Camera $A$ ) with a macrolens for magnification was used to obtain a grazing angle view of the ice accretion. The camera was focused at the stagnation region near the center of the test section. An additional video camera (Camera B) was mounted slightly upstream of the cylinder to provide a view of the ice accretion looking normal to the cylinder surface. Secondary lighting was provided to obtain a clear video record of the accreting ice surface. A second grazing angle camera (Camera C) was also used in some cases to provide a less magnified view of the overall ice shape.

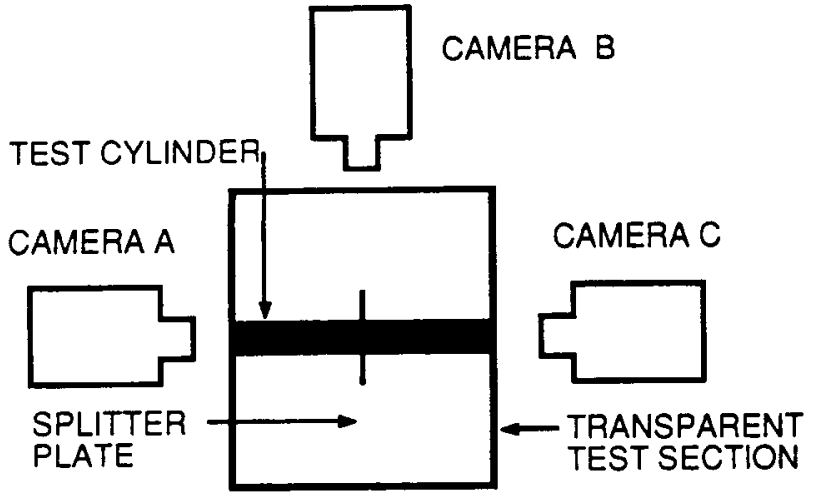

Fig. 1. Schematic view of the photographic setup for the DP and BFG icing tunnels.

The experimental setup used in the IRT tests is shown in Fig. 2. The photographic and test cylinder geometry is very similar to the DP and BFG grazing angle camera setup described above. However, in order to locate the test cylinder within the region of uniform cloud, both the test cylinder and the camera had to be moved into the tunnel. A heated waterproof fairing was provided to protect the camera. In addition, a shutter was located upstream to shield the test cylinder during initial transients in the liquid water content. Once the tunnel spray system had stabilized, the shield was removed and the cylinder began to ice. The nominal MVD used in the IRT tests was 20 microns.

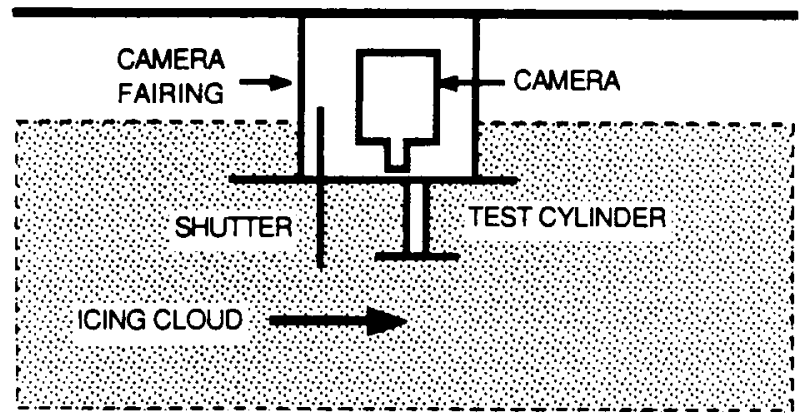

Fig. 2. Schematic view of the photographic setup in the IRT.

\subsection{Infrared Video Setup}

The IR thermal video system setup used in the BFG tests is shown in Fig. 3. The IR camera was mounted above the test section. Because no IR transparent windows were available, a viewing slot was cut into the top of the tunnel so that the cylinder could be viewed directly. The IR video system provided color thermographs of the accreting ice surfaces and temperature profiles along designated sections. The system was typically operated with the cooler temperature scale set to $0.5^{\circ} \mathrm{C}$ and a dynamic range set between the tunnel operating temperature and $0^{\circ} \mathrm{C}$. Cold air blowing out of the viewing slot cooled the IR optics and caused the absolute calibration of the system to drift. The system was, therefore, calibrated "in situ" by viewing points of known temperature while the tunnel was operating.

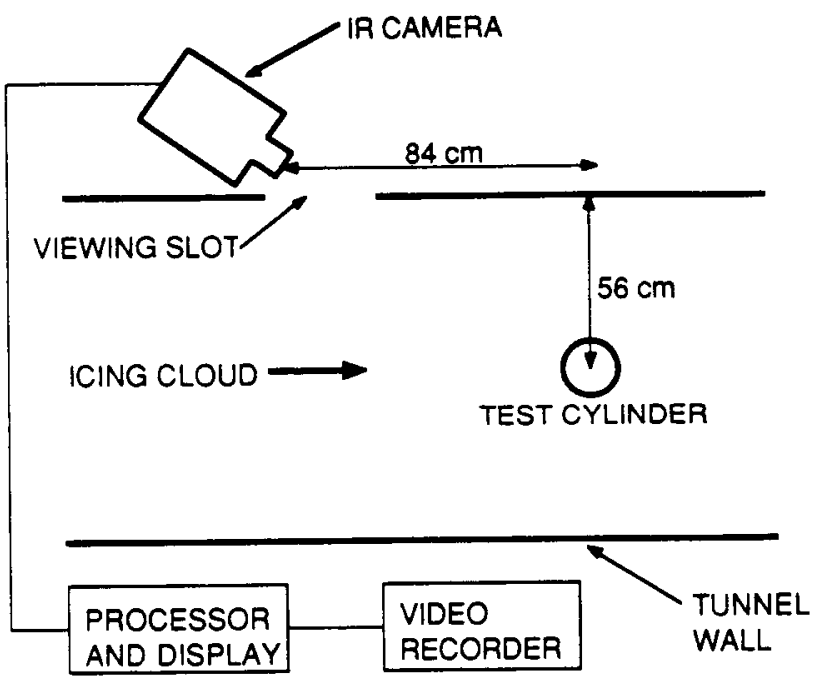

Fig. 3. Schematic view of the IR video system setup in the BFG icing tunnel.

\subsection{Experimental Observations of Ice Surface Roughness}

\subsection{Surface Roughness Zones}

During the detailed photographic analyses of accreting ice surfaces, distinct regions were observed each having a characteristic roughness and identifiable boundaries. A total of 5 roughness zones were identified although rarely were more than 3 present on any particular ice accretion. The 5 zones are described briefly below.

\subsubsection{Smooth Zone}

In glaze ice accretions, close to the stagnation point, the surface was observed by light reflection and IR techniques to be uniformly wet with a thin film of water at warm temperatures. The surface in this regime was smooth, with no distinctly visible roughness. The ice was translucent within the smooth zone. The extent of the smooth zone can be seen in Fig. 4 which shows a representative final glaze ice shape for a $3 \mathrm{~min}$. icing exposure at $150 \mathrm{kts}$ and $-4.5^{\circ} \mathrm{C}$ at a liquid water content of 0.4 $\mathrm{g} / \mathrm{m}^{3}$ in the DP tunnel. Similar accretions were observed in IRT and BFG facilities. 


\subsubsection{Rough Zone}

At some point downstream, there was a sudden transition to a significantly rougher surface. This can be seen in Fig. 4 Within this zone, there appeared to be insufficient water to maintain a uniform film. Surface tension forces dominated the water surface behavior. Runback did not occur, rather, the water tended to coalesce into the water beads first observed by Olsen, et al 4,5 . The scale length of the roughness was typically on the order of $1 \mathrm{~mm}$.

Inasmuch as there was a distinct boundary between the smooth and rough zones this position could be easily identified on the grazing angle video recording. The angular position of this boundary is plotted as a function of the time in Fig. 5 for the accretion shown in Fig. 4. The transition is observed to propagate rapidly towards the stagnation region. This behavior was observed in all three test facilities (DP,IRT,BFG). The repeatable nature of the smooth-rough transition's propagation towards the stagnation region implies a clear underlying physical mechanism for the transition between the surface water behavior in the smooth and rough zones. This is discussed in more detail in Section 3.2.

The ice accretion rate was observed to be enhanced in the rough zone as compared with the smooth zone. This can be seen in the ice profile shown in Figure 4. The enhanced accretion rate is thought to be due to increased heat transfer resulting from the greater surface roughness in this zone. In all the cases observed in this study, the ice horns characteristic of glaze ice accretion were found within the rough zone.

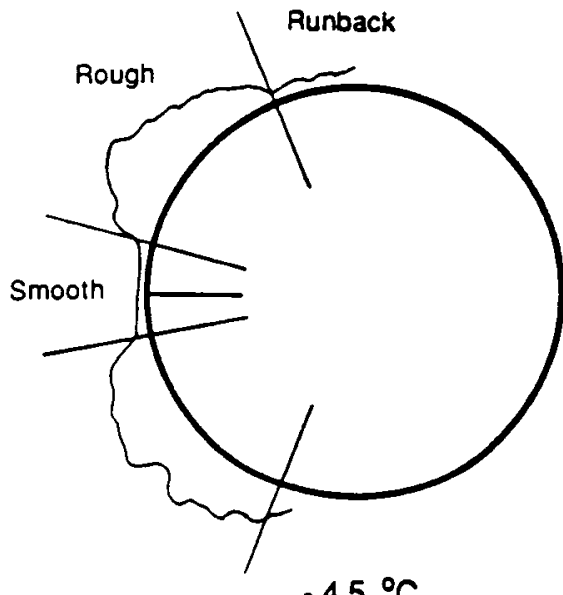

Fig. 4. Typical final glaze ice shape showing distinct roughness zones, $\left(T=.4 .5^{\circ} \mathrm{C}, W=1.0 \mathrm{~g} / \mathrm{m}^{3}\right)$.

\subsubsection{Horn Zone}

In certain glaze ice accretions particularly at high liquid water contents, some of the roughness elements within all or part of the rough zone were observed to grow into distinct protuberances. An example of such a case is shown in Fig. 6 for a very warm $\left(-0.5^{\circ} \mathrm{C}\right)$ glaze ice accretion. Once these elements extended far enough above the ambient surface, they became essentially separate microscopic ice accretions with high collection efficiencies catching droplets which would otherwise have been swept by the accreting body. Because of the collection efficiency and the enhanced heat transfer of these protuberances they tended to grow rapidly resulting in horned ice accretions. In some warm cases such as the one shown in Fig. 6, water was observed to be torn or shed from the individual elements. This results in a water flow mechanism which is not considered in any present ice accretion models.

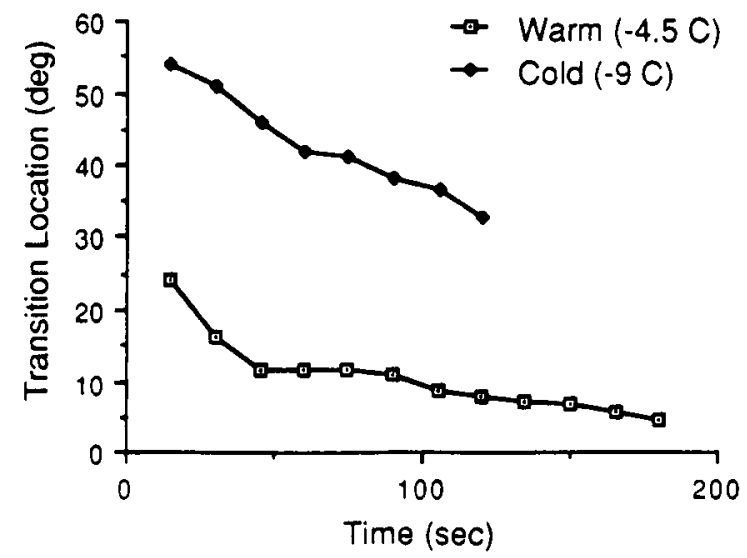

Fig. 5. Angular position versus time of smooth-rough transition location for two air temperatures.

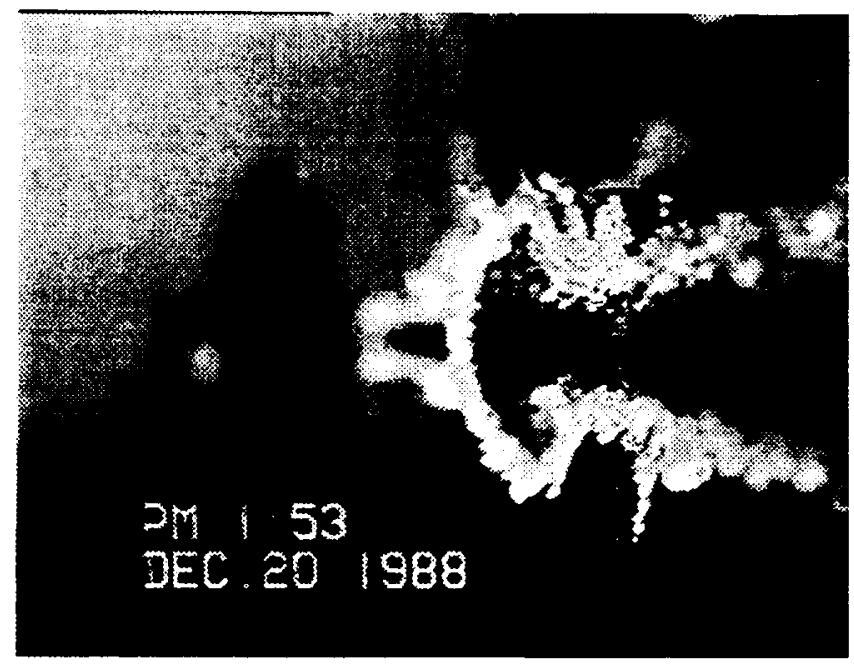

Fig. 6. Extreme example of horn elements for a warm glaze ice accretion $\left(-0.5^{\circ} \mathrm{C}\right)$.

\subsubsection{Runback Zone}

At warm temperatures a runback zone was observed aft of the rough zone in the primary accretion. An example can be seen in Figure 4. This region was characterized by areas of ice interspersed with uniced surface. This ice was observed to form during an initial transition period after cloud exposure. The ice was translucent, and quite often frozen rivulets could be discerned. In warm conditions and high liquid water contents, the surface water was observed to inirially runback and then stagnate at the point of flow separation. This water then slowly froze as rivulets or as large coalesced water cells. Once ice began to form in the upstream rough zone, no additional surface water was supplied to the runback zone and the ice surface remained constant.

\subsubsection{Rime Feather Zone}

At cold temperatures rime feathers are sometime observed to grow in the region aft of the primary accretion. The feathers were observed by the IR Video System to be dry ice accretions and propagate in the local upstream direction. It should be noted that there are intermediate conditions where neither runback or rime feathers are observed. 


\subsection{Effect of Icing Cloud Parameters on the Rough to Smonth Transition}

The effect of icing cloud parameters on the transition between the smooth and rough surface zones was observed in an attempt to identify the underlying physical mechanisms which cause the rough surface to develop. The transition between the smooth and rough surface zones was monitored as a function of time for a variety of cloud conditions in the DP tunnel. The temperature, liquid water content and free stream velocity effects were studied individually by holding all other parameters constant at nominal values and comparing transition behavior. The nominal velocity was $150 \mathrm{kts}$, the nominal liquid water content was approximately $0.4 \mathrm{~g} / \mathrm{m}^{3}$ with a mass of 30 microns, and the nominal temperature was $-4.5^{\circ} \mathrm{C}$

The effect of cloud temperature, liquid water content and free stream velocity on the angular position of transition are shown as a function of time in Figs. 5, 7 and 8 respectively. In each case the transition point is observed to migrate towards the stagnation point as discussed above. However, a significant variation was observed in the actual transition location. It can be seen that warmer temperatures, increasing liquid water content and increasing velocity tend to move the transition point closer to the stagnation region. These observations tend to imply that increasing Reynolds number and increasing the flow of surface water cause the smooth to rough transition point to move closer to the stagnation region.

The observed Reynolds number dependance may indicate that, in certain conditions, the initial transition in surface roughness is controlled by the boundary layer. In these cases the laminar to turbulent boundary layer transition point will also be the initial smooth to rough transition point. The enhanced heat transfer in the turbulent region would cause sufficient freezing to partially dry the surface and cause bead formation. Whereas, in the laminar region, the heat tuansfer is low enough that the surface is coated by a uniform water film. Once the roughness zone emerges, the roughness elements themselves will cause the transition of the boundary layer if it is not fully turbulated.

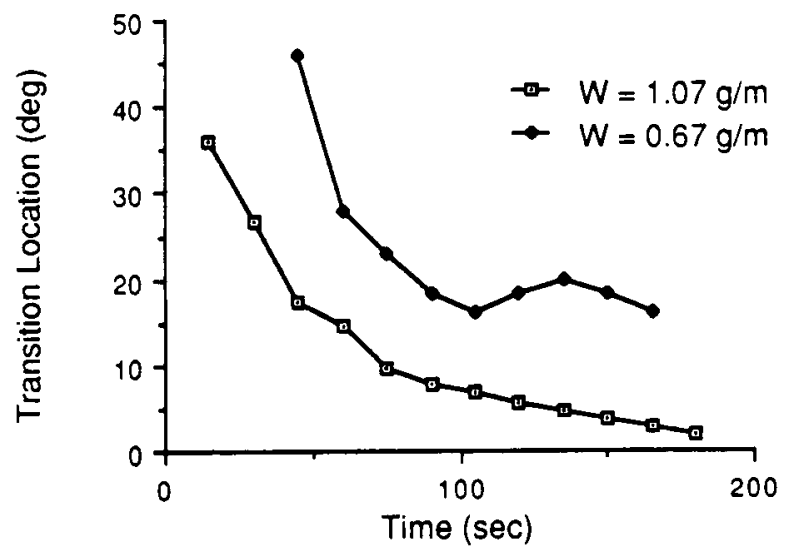

Fig. 7. Angular position versus time of smooth-rough transition location for two cloud liquid water contents.

In order to more fully evaluate this hypothesis, the initial location of the rough to smooth transition was observed as a function of Reynolds number based on cylinder diameter for a variety of icing conditions in the IRT and BFG tunnels. The results are shown in Fig. 9. While there is some scatter in the data the initial rough to smooth transition is generally observed to move towards the stagnation point with increasing Reynolds number. Also shown are the theoretical locations of the boundary layer transition based on a critical roughness element

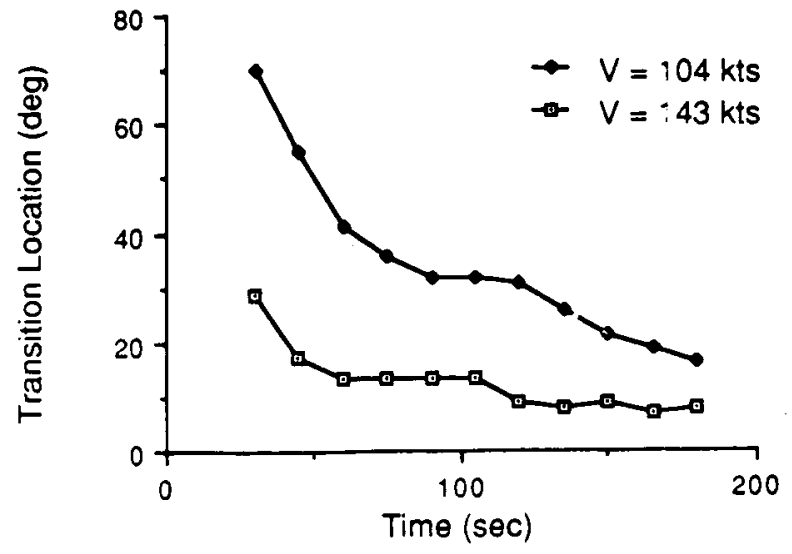

Fig. 8. Angular position of smooth-rough transition versus time for two free stream velocities.

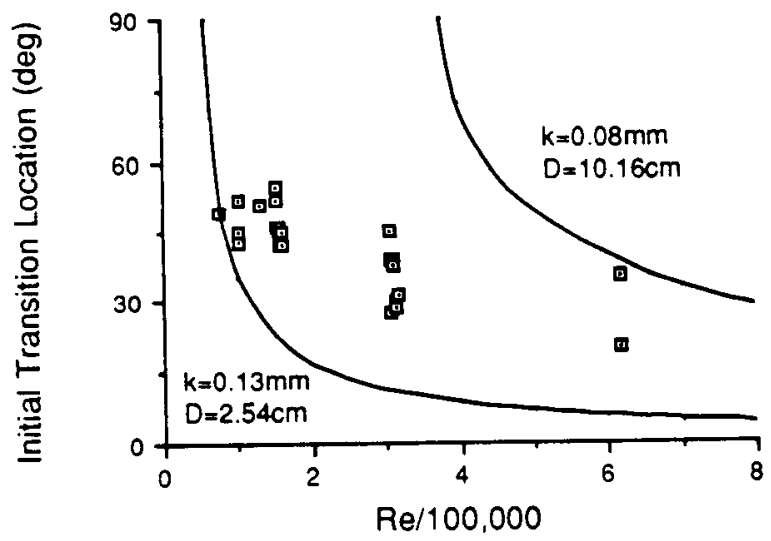

Fig. 9. Initial transition location versus Reynold's number.

Reynolds number of 600 for $0.13 \mathrm{~mm}$ roughness elements on a 1 " cylinder and $0.08 \mathrm{~mm}$ roughness elements on a 4 " cylinder. 6 The experimental data are bracketed by the boundary layer transition curves. Considering that the roughness in the wet stagnation region is likely to decrease with increasing Reynolds number, the experimental results do not appear to contradict the hypothesis that the initial rough to smooth transition is a result of boundary layer transition.

The influence of surface water flow on the rough to smooth transition location indicates that dynamic effects are also important. It is thought that the dynamic effects are caused by bead formation at the interface between the smooth and rough surface zones as is shown in Fig. 10. The formation of these beads at the interface causes enhanced heat transfer within the rough zone which tends to freeze out the downstream beads and dry the surface. As the surface drys, beads begin to form further upstream and the transition point will propagate towards the stagnation region as observed experimentally. By increasing the surface water flux, the rate of formation and growth of the interfacial beads is increased. This causes the observed increase in upstream propagation of the transition point with surface water flux.

Further experimental observations are under way to more fully determine the boundary layer and dynamic mechanisms which cause the transition in surface roughness. 


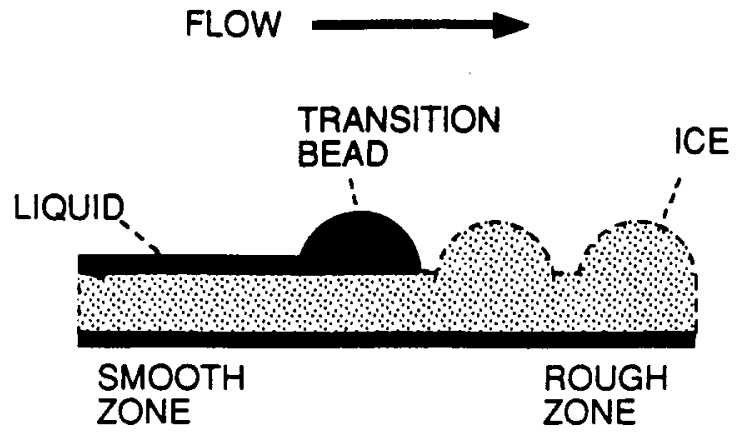

Fig. 10. Schematic representation of bead formation at the smooth to rough transition.

\subsection{Infrared Observations}

Typical digitized video images of a 2.5 " cylinder during a $2 \mathrm{~min}$. $15 \mathrm{sec}$. icing encounter in the BFG tunnel are shown in Fig. 11 . In this case the temperature was $-4^{\circ} \mathrm{C}$, the velocity was $150 \mathrm{kts}$ and the liquid water content was $1.5 \mathrm{gm} / \mathrm{m}^{3}$. The IR camera was located $56 \mathrm{~cm}$ above and $84 \mathrm{~cm}$ upstream of the cylinder as shown in Fig. 3. As a result the cylinder was observed from above the horizontal and only the top of the cylinder was in view. In the images, the flow would be from below and a thermal profile corresponding to the mid-plane of the tunnel is shown on the right.

Prior to exposure to the icing cloud, in Fig. 11a the cylinder was at a uniform temperature of $-4^{\circ} \mathrm{C}$ corresponding to the tunnel stagnation temperature. When the spray was turned on the stagnation region quickly warmed to $0^{\circ} \mathrm{C}$ indicating wet growth. The wet region spread for approximately $75 \mathrm{sec}$ until it reached equilibrium covering the foreword $50^{\circ}$ of the cylinder. The equilibrium wet region can be seen in Fig. 11b. As horned growth began to appear in the wet region, the boundary of the wet region became irregular as exhibited in Fig 11c. The enhanced heat transfer and the variation resulting from the rough surface and the homs can be seen in Fig. 11d which was taken $10 \mathrm{sec}$. after the spray was shut off. At this time a small wet region can still be observed in the stagnation area due to the low heat transfer in that region.

The extent of the wet surface region was studied using the $\mathbb{R}$ video system for a variety of conditions. It was found that both the surface roughness and horns were generated within the wet region. However, rime feathers were always observed in the dry region. The wet region was always centered around the stagnation line and its extent varied as a function of icing conditions, particularly temperature. The angular extent of the wet region is plotted as a function of temperature in Fig 12.

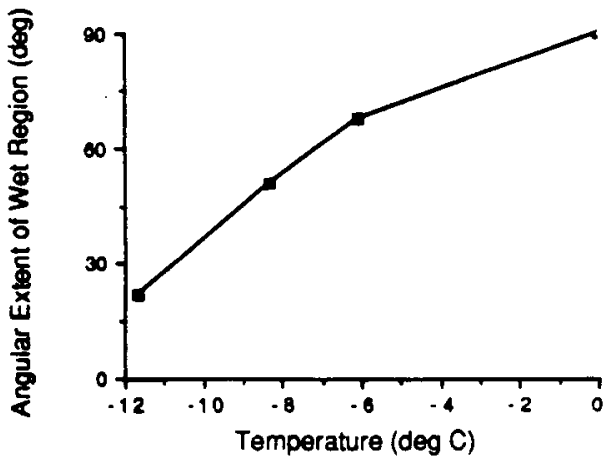

Fig. 12. Angular extent of wet region as a function of temperature for 2.5" cylinders in the BFG tunnel, $\left(\mathrm{V}=150 \mathrm{kts} ., \mathrm{W} \cdot 1.0 \mathrm{~g} / \mathrm{m}^{3}\right)$.
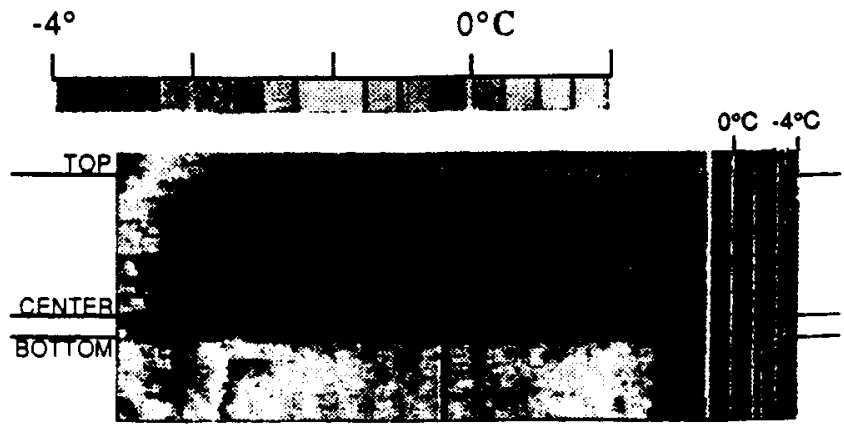

a.)

Before icing cloud exposure.

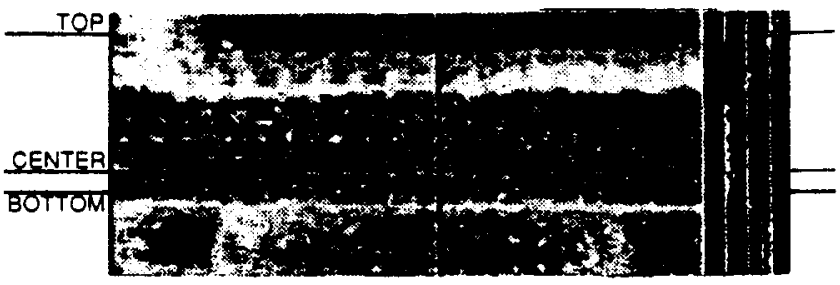

b.)

75 sec after exposure began.

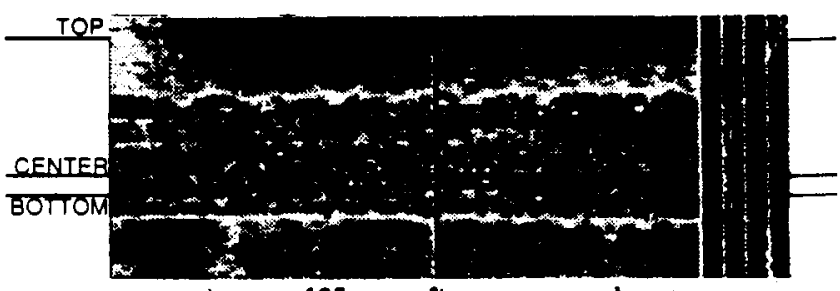

c.)

135 sec after exposure began.

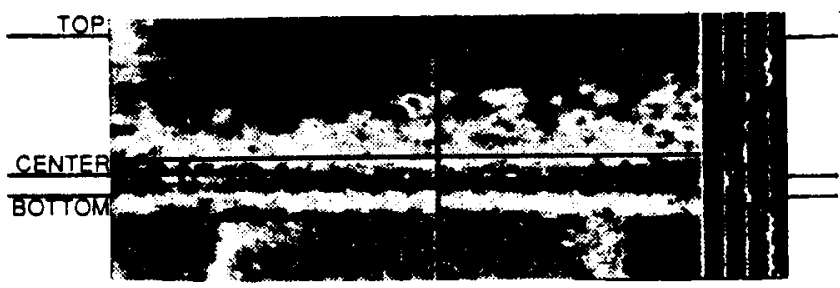

d.)

$10 \mathrm{sec}$ after exposure ended.

Fig. 11. Infrared thermographs of a 2.5" cylinder in the BFG tunnel, $\left(T=.4^{\circ} \mathrm{C}, V=150 \mathrm{kts}, W=1.5 \mathrm{~g} / \mathrm{m}^{3}\right)$.

4.0 Preliminary Implementation of a Multi-Zone

\subsection{Model Description}

Based on the observations of surface water behavior during glaze ice accretion, a relatively simple modification to the existing ice accretion model is proposed which may improve the current model's accuracy within the glaze ice regime. In this proposed "Multi-Zone" model, the accreting ice surface is divided into two or more discrete zones which have varying surface water behavior and surface roughness. This is in contrast to current techniques which assume that the surface has uniform roughness and surface water runback.

In the simplest version of the model, the surface is divided into two zones. There is a "smooth" wet zone corresponding to the smooth zone described in Section 3.1. It is centered about the stagnation region and thin film runback occurs within the zone. In this region, the heat transfer would be that for a smooth surface and the Messinger ${ }^{7}$ type runback model used in existing codes such as LEWICE appears to be valid. No change in the existing codes is considered necessary in the smooth zone. 
The remaining ice surface would consist of a "rough" zone where surface tension effects are important and characteristic water beads or roughness elements appear. Within this rough zone the existing Messinger runback model is not appropriate for two reasons. First, the increased roughness will enhance the heat transfer and consequently increase the freezing fraction. Second, experimental observations by Olsen and Hansman $3,4,8,9$ indicate that in some cases, surface water does not run back in the rough zone. In most cases surface tension forces dominate the water behavior and the beads remain stationary on the surface. At warm temperatures, high liquid water contents or high velocities, the beads may grow large enough that aerodynamic forces cause the beads to either slide aft on the surface or be tom from the surface and shed into the airflow.

In the absence of runback, the freezing fraction can be assumed to be unity within the rough region. This assumption obviates the need to calculate the convective heat transfer coefficient and the effective surface roughness which greatly simplifies the ice accretion model. In the presence of runback or sliding, the freezing fraction is less than unity and must be computed by the model through the Messinger heat balance approach with appropriate heat transfer coefficients corresponding to the enhanced roughness. In some cases it may be adequate to approximate the spatial variation of the freezing fraction by linear interpolation between the smooth zone value and unity at the point where rough zone ends or the surface is dry.

In the presence of shedding, the modeling is more complex. Some mechanism must be included to model the shedding process and the increased roughness within the rough zone. One approach would be to determine a maximum unfrozen water thickness for each element based on the local flow velocity. If the water layer in the element exceeds this value the water is shed from the surface in the model to both the runback and heat transfer. The roughness within the rough zone could then be modeled as the maximum stable droplet size.

Because the boundary between the rough and smooth zones moves with time it is necessary to incorporate this into the model. Since most ice accretion codes run a limited number of time steps, it was found to be convenient to include a third transition zone between the rough and smooth zones as shown in Fig.13. For cases where there is no runback in the rough zone the transition extends between the location of the rough to smooth transition at the beginning and end of the time step. For cases where there is runback in the rough zone the transition region would extend between the rough to smooth zone transition to the end of the rough zone or the point at which there is no further runback. Under these assumptions, the freezing fraction can simply be ramped up in the transition zone from the smooth zone value to unity. It should be noted that, in principle, the surface roughness could be varied instead of the freezing fraction. This was attempted; however, difficulties were encountered in correlating the effective heat transfer and equivalent sand grain roughness used in LEWICE with physical values. Therefore, the freezing fraction approach was employed in these preliminary evaluations.

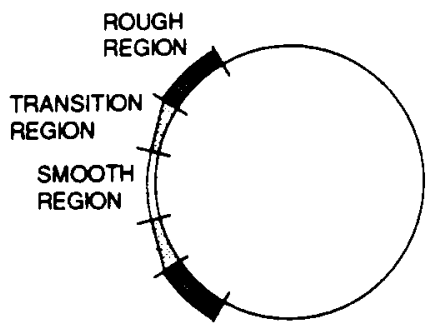

Fig. 13. Schematic representation of zones used in the model.

\subsection{Results}

A prototype of the proposed "multi zone" model was implemented in the LEWICE code to evaluate the effectiveness of the concept. In this preliminary model the rough to smooth transition location and the extent of the wet growth region were taken from experimental observations. The intermediate and

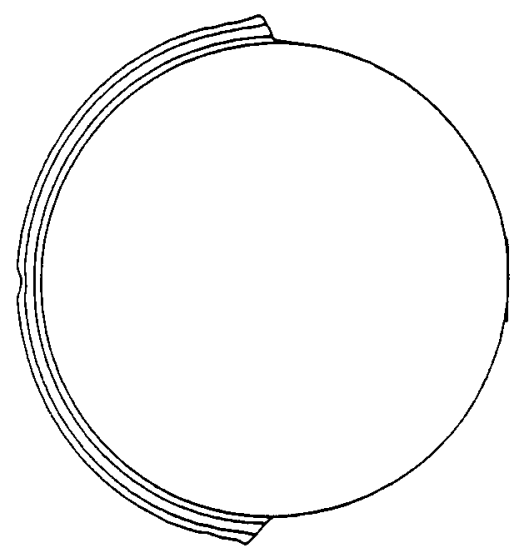

a.)

Normal LEWICE at 45, 105, and 150 secs.

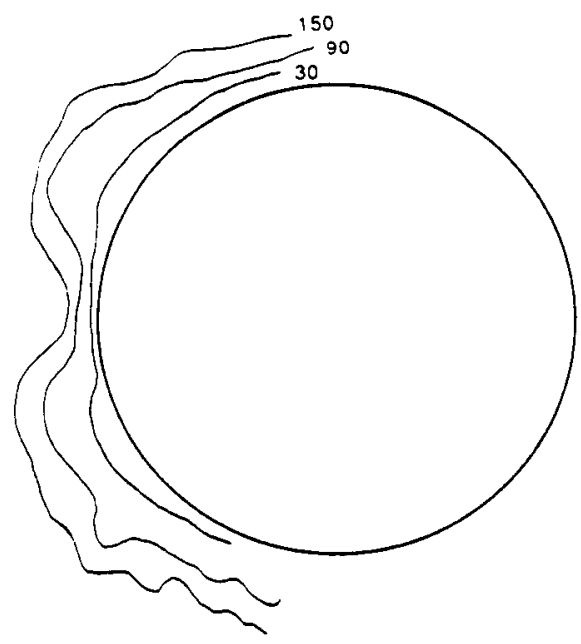

b.) Experimental result at 30,90 , and 150 secs.

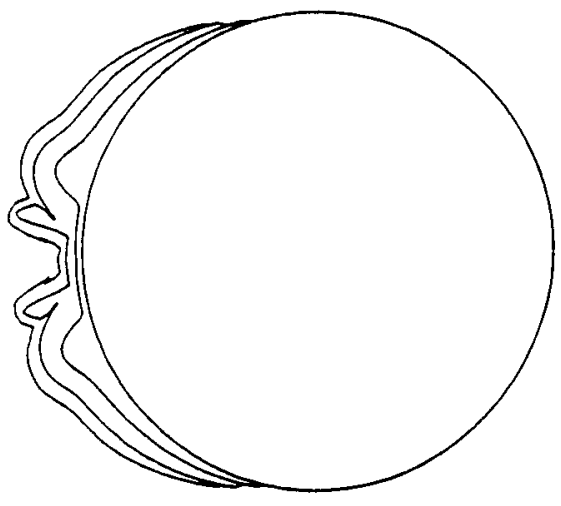

c.) Modified LEWICE at 45,105 , and 150 secs.

Fig. 14. Comparison of predicted and experimental ice shapes for a $1^{\prime \prime}$ cylinder, $\left(T=-4.5^{\circ} \mathrm{C}, V=150 \mathrm{kts}\right.$, $W=0.35 \mathrm{~g} / \mathrm{m}^{3}$ ). 
final ice accretions profiles were compared with experimentally measured profiles for several cases.

The first comparison was conducted for a low liquid water case of $0.35 \mathrm{~g} / \mathrm{m}^{3}$ on a 1 "cylinder in the DP tunnel at $-4.5^{\circ}$ $C$, and $150 \mathrm{kts}$ Since there was little or no runback in this case the freezing fraction was ramped linearly through the transition zone from the smooth zone value to unity in the rough zone. The comparisons between the experimentally measured ice shapes and those predicted by the multi-zone LEWICE code and the normal LEWICE code with the Ruff roughness correlations 10 are shown in Fig. 14. It can be seen that there is a significant improvement in fidelity of the overall ice shape for the multizone case. There is however an irregularity in the ice surface which appears in the second time step and is thought to be an artifact of the ramped freezing fraction combined with the long time steps. The irregularity is located at the point where the freezing fraction becomes unity. Because of the relatively long time steps used in the simulation runback water collects at this point resulting in the observed bulge. Efforts are under way to minimize this effect in a physically realistic and numerically acceptable manner. In general, however the multi-zone LEWICE predicts the essential components of the ice accretion whereas the normal LEWICE prediction is not at all representative of the experimentally observed ice shape.

The second comparison was conducted for a high liquid water case of $1.5 \mathrm{~g} / \mathrm{m}^{3}$ on a $2.5^{\prime \prime}$ cylinder in the BFG tunnel at $4.0^{\circ} \mathrm{C}$, and $150 \mathrm{kts}$. In this case the rough to smooth transition reached the stagnation point by $60 \mathrm{sec}$ as shown in Fig. 15. After this time the cylinder was uniformily rough with a roughness element size estimated at 2 to $3 \mathrm{~mm}$ from the grazing angle video. Runback was observed in the rough zone and the wet region was observed by the IR video system to extend to $60^{\circ}$. Since there was runback in the rough zone, the transition region in the multi-zone model extended from the rough to smooth transition point to the observed dry surface at $60^{\circ}$. It should also be noted that the liquid water content was reduced b; a factor of 2 during the first 30 second time step to account for start up transients in the spray system.

The comparisons are shown in Fig. 16. There is excellent agreement between the multi-zone model and the experimental ice shapes for the first $60 \mathrm{sec}$ while there were multiple roughness zones on the icing surface. The normal LEWICE code significantly underpredicted the ice accretion. After $60 \mathrm{sec}$ simulation of the further accretion was simulated by running the normal LEWICE code on top of the $60 \mathrm{sec}$ ice shape

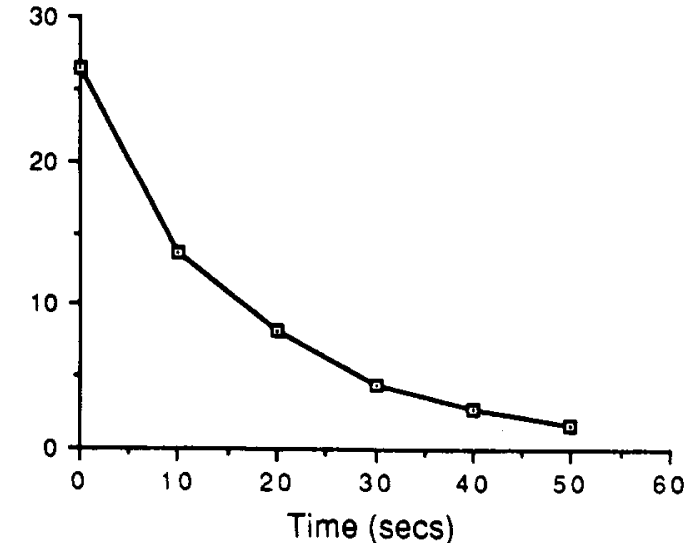

Fig. 15. Angular position versus time of smooth-rough transition location for the high liquid water content example. using an equivalent sand grain roughness of $3 \mathrm{~mm}$ corresponding to the observed physical roughness. This resulted in an extremely low freezing fraction of approximately 0.005 over the entire surface and generated almost no further accretion. Larger values of surface roughness were also used; however, the freezing fraction did not increase significantly.

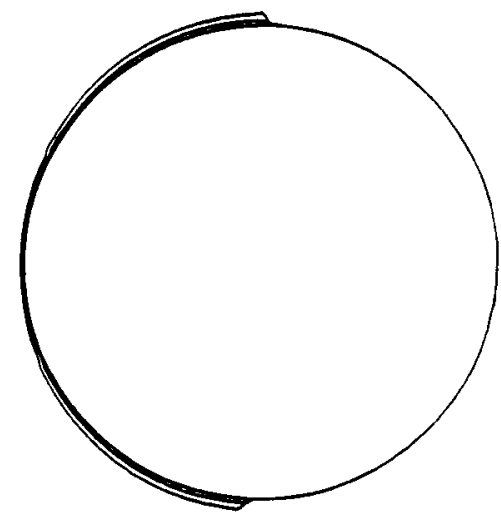

a.) Normal LEWICE at 30 and 60 secs.

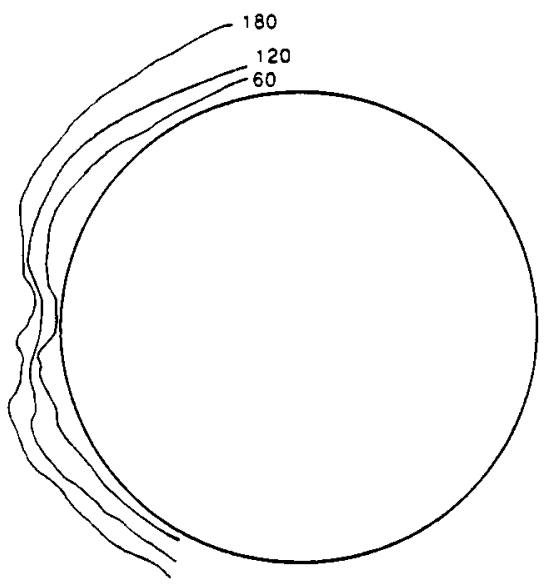

b.) Experimental result at 60,120 , and 180 secs.

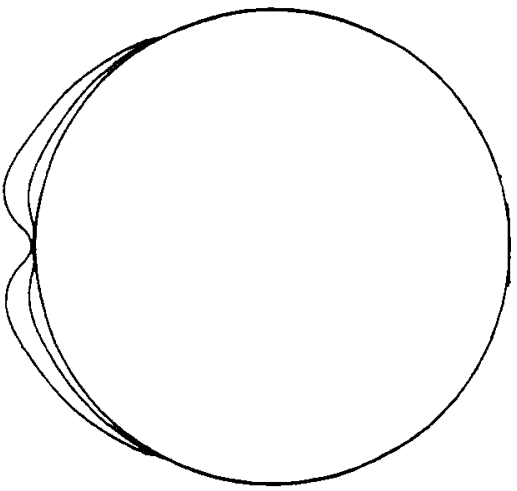

c.) Modified LEWICE at 30 and 60 secs.

Fig. 16. Comparison of experimental and predicted ice shapes for a $2.5^{\prime \prime}$ cylinder, $\left(T=-4^{\circ} \mathrm{C}, V=150 \mathrm{kts}\right.$, $\left.\mathrm{W}=1.5 \mathrm{~g} / \mathrm{m}^{3}\right)$. 
The LEWICE code clearly underpredicted the heat transfer for this case. In the normal LEWICE code surface roughness is used to adjust the heat transfer model. This illustrates the need for an improved treatment of the heat transfer if surface roughness is to be deterministically included in ice accretion models.

\subsection{Conclusions}

The investigation into modeling of surface roughness effects on glaze ice accretion has resulted in the following:

1. Accreting glaze ice surfaces have been observed to have distinct zones of surface roughness. They include: a smooth wet zone in the stagnation region where uniform film runback occurs, a rough zone where surface tension causes coalescence of the surface water into beads, a horn zone which can emerge out of the rough zone with large roughness elements, a runback zone where surface water runs back as rivulets, and a zone where rime feathers grow.

2. The location of the transition point between the smooth and rough zone was observed to propagate with time towards the stagnation point.

3. The initial location of the surface roughness transition point appears to be related to the transition of the boundary layer from laminar to turbulent. The propagation of the transition point appears to be related to the rate of bead formation at the interface between the rough and smooth zones.

4. Infrared video observations were made of accreting ice surfaces. This technique was used to investigate the extent of wet regions on the ice surface and also measured heat transfer enhancements resulting from roughness and horn elements.

5. Based on the above, a preliminary modification to the LEWICE ice accretion code which incorporates multiple roughness zones was proposed.

6. The proposed multi-zone modifications were implemented using experimental data to determine factors such as the rough to smooth transition locations. The muli-zone modifications significantly improved the performance of the code as compared with the normal LEWICE code. Based on the good performance of the preliminary multi-zone code, further efforts to develop a more fully deterministic and operational version of the code appear to be warranted.

\section{Acknowledgments}

This work was supported in part by the National Aeronautics and Space Administration and the Federal Aviation Administration under Grants NAG-3-666 and

NGL-22-009-640. The work was also supported by the National Science Foundation Presidential Young Investigators

Program, Award No. 8552702 . Use of the icing wind tunnel facilities were provided courtesy of Data Products of New England, B. F. Goodrich Deicing Systems and the NASA

Lewis Research Center. Dr. James Riley of the FAA Technical

Center provided valuable input to the modeling efforts.

\section{References}

1. Achenbach, E., "The Effect of Surface Roughness on the Heat Transfer from a Circular Cylinder to the Cross Flow of Air," International Journal of Heat Mass Transfer, Vol. 20, 1977, pp. 359-369.

2. MacArthur, C.D., "Numerical Simulation of Airfoil Ice Accretion," AIAA Paper 83-0112, Jan. 1983.

3. Gent, R.W. and Cansdale, J.T., "The Development of Mathematical Modeling Techniques for Helicopter Rotor Icing," AIAA Paper 85-0336, Jan. 1985.

4. Olsen, W., and Walker, E., "Closeup Motion Pictures of the Icing Process," NASA LeRC Film, 1983.

5. Olsen, W.A., and Walker, E.,"Experimental Evidence for Modifying the Current Physical Model for Ice Accretion on Aircraft Structures", NASA TM 87184, 1987.

6. von Doenhoff, A.E., and Horton, E.A., "A Low Speed Experimental Investigation of the Effect of Sandpaper Type of Roughness on Boundary-Layer Transition", NACA TN $3858,1956$.

7. Messinger, B.L., "Equilibrium Temperature of an Unheated Icing Surface as a Function of Airspeed," Journal of the Aeronautical Sciences, Jan. 1953, pp. 24-42.

8. Hansman, R.J., and Turnock, S., "Investigation of Surface Water Behavior During Glaze Ice Accretion", AIAA Paper 88-0115, Jan. 1988.

9. Hansman, R.J., and Turnock, S., "Investigation of Microphysical Factors Which Influence Surface Roughness During Glaze Ice Accretion", Proc. 4th Intl. Workshop on the Atmospheric Icing of Structures, Sept. 1988.

10. LEWICE Users Manual, 1988. 